\title{
Low Profile Tunable Dipole Antenna Using BST Varactors for Biomedical Applications
}

\author{
David Cure* and Thomas M. Weller \\ Dept. of Electrical Engineering \\ University Of South Florida \\ Tampa, FL, 33620 \\ E-mail: dcure@mail.usf.edu
}

\author{
Félix A. Miranda \\ Antenna and Optical Systems Branch \\ NASA John H. Glenn Research \\ Cleveland, OH 44135 \\ E-mail: felix.a.miranda@nasa.gov
}

\author{
Tony Price \\ Intel Corporation \\ Chandler, AZ, 85226 \\ E-mail: tony.price@intel.com
}

\begin{abstract}
In this paper a $2.4 \mathrm{GHz}$ low profile $(\lambda / 47)$ tunable dipole antenna is evaluated in the presence of a human core model (HCM) body phantom. The antenna uses a frequency selective surface (FSS) with interdigital barium strontium titanate (BST) varactor-tuned unit cells and its performance is compared to a similar low profile antenna that uses an FSS with semiconductor varactor diodes. The measured data of the antenna demonstrate tunability from $2.2 \mathrm{GHz}$ to $2.55 \mathrm{GHz}$ in free space and impedance match improvement in the presence of a HCM at different distances. This antenna has smaller size, lower cost and less weight compared to the semiconductor varactor diode counterpart.
\end{abstract}

\section{INTRODUCTION}

Herein an endloaded planar open sleeve dipole (ELPOSD) antenna backed with a barium strontium titanate (BST) varactor-loaded

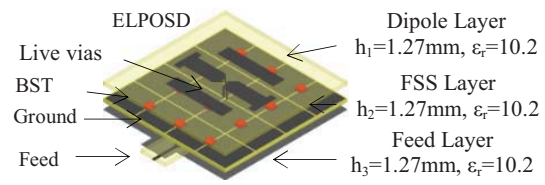

Figure 1. Schematic of the ELPOSD antenna illustrating the multi-layer substrate with feed layer, tunable FSS layer, and dipole.

frequency selective surface (FSS) for contactless biomedical radiometer applications is evaluated (Fig. 1). Specifically, the BST-based antenna is compared to previous design by Cure [1] in the presence of a human core model (HCM) phantom which mimics a conical volume of the human stomach. The antenna has a total thickness (excluding the feed layer) of $\sim \lambda / 47$ at the center of the operating band.

The main features of this antenna are its potentially conformal nature and absence of vias for ground connection, low profile, low cost, small size high robustness and tunability. The significance of these features stems from the intended use of the antenna for contactless biomedical radiometric sensing applications where natural variations in the permittivity of the composite tissue structure, which depend on the percentages of fat, bone and muscle, as well as variations in the separation distance between the sensor antenna and the tissue, can induce impedance mismatches and dramatic changes in the thermallyinduced electromagnetic energy transfer between the patient (or subject) and the sensor. Furthermore, accurate interpretation of radiometric data obtained within a single frequency band is complicated by these same variations. A broadband or a multiband antenna with moderate instantaneous bandwidth enables maximum temperature resolution, which is critical in detecting subsurface emissions from internal tissue and organs. Thus, the ability to dynamically adjust the center frequency and impedance match the sensor antenna is desirable [2].

Two antenna designs are discussed and compared among themselves based on height, weight, size, performance, cost and robustness. Previous works [1-4] have demonstrated adequate impedance match in the presence of the HCM, which is necessary to maintain the sensitivity of the radiometer. The works in [2-4] present high efficiency and broadband antennas; however, the designs are not electronically-tunable and impose height and weight constraints for the intended application. Such approaches are thus impractical for use in portable biomedical applications. In [1], a low profile tunable antenna design with moderate efficiency and good performance in the presence of the HCM is presented. However, the design is relatively high cost, has a large planar size and lacks robustness due to the fragile nature of the semiconductor material (GaAs in this case). External packaging would be required for added robustness which ultimately increases the overall size of the antenna and its cost. In this paper, an antenna with similar performance in free space as compared with [1] is evaluated; size, mass and height reduction, high robustness (given the alumina substrate material onto which the BST is deposited) are achieved.

In the following sections, the BST tunable antenna design is presented, along with an evaluation of the impedance match performance of the antennas in the presence of the HCM for different offset distances. All simulation results shown herein were obtained using Ansoft's High Frequency Structure Simulator (HFSS) software.

\section{ANTENNA DESIGN AND PERFORMANCE}

The antenna was designed to operate at a center frequency of $2.4 \mathrm{GHz}$ and built on a 1.27 mm-thick

Rogers RT6010 substrate, with a dielectric constant of 10.2 . It has a planar size of $94 \times 84$

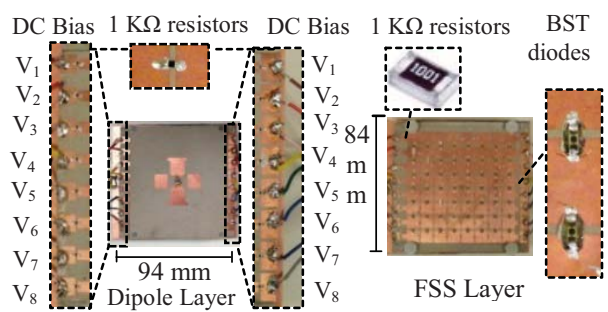

Figure 2. Antenna assembly showing the dipole layer and the tunable FSS ground plane with 8 independent voltage ports and resistors to isolate the RF leakage from the bias lines.

$\mathrm{mm}^{2}$, including the bias network. The FSS consists of 64 tunable unit cells and 56 BST varactors. The antenna has eight independent DC voltage lines, on which the odd lines $\left(\mathrm{V}_{1}, \mathrm{~V}_{3}, \mathrm{~V}_{5}\right.$, $\mathrm{V}_{7}$ ) are biased at the same voltage but opposite polarity with respect to the even lines $\left(V_{2}, V_{4}, V_{6}, V_{8}\right)$ to create a virtual ground between them (Table I). This bias network capitalizes on the symmetric behavior along the zero-bias voltage axis in the $\mathrm{C}-\mathrm{V}$ curve. 
Measured $\mathrm{S}_{11}$ data for the antenna in free space when applying common bias voltage of $0 \mathrm{~V}$, $\pm 30 \mathrm{~V}$ and \pm 50 $\mathrm{V}$ to the DC bias ports are shown in Fig. 3 (left).
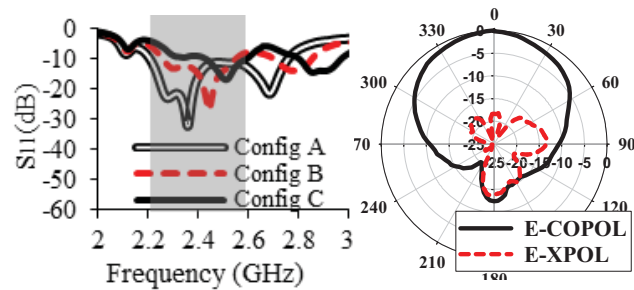

Figure 3. Measured $\mathrm{S}_{11}$ when $0 \mathrm{~V}$ (Config A), $\pm 30 \mathrm{~V}$ (Config B), and $\pm 50 \mathrm{~V}$ (Config C) is applied to all DC bias lines. Radiation patterns for the antenna with bias voltage of $30 \mathrm{~V}$ at $2.4 \mathrm{GHz}$ (right).

Using the $10 \mathrm{~dB}$ return loss criterion, there is a $\sim 400 \mathrm{MHz}$ span between the low end of the response with $0 \mathrm{~V}$ and the high end of the response using $50 \mathrm{~V}$ (from $2.2 \mathrm{GHz}$ to $2.55 \mathrm{GHz}$ ). The radiation pattern with bias voltage of $\pm 30 \mathrm{~V}$ shown in Fig. 3 (right) demonstrates cancellation of back radiation and a high cross-polarization ratio. For electromagnetic sensing, such as in the case of radiometric sensors, reduction in backside radiation is important in order to maximize the detection sensitivity.

TABLE I. FSS BIAS CONFIGURATIONS

\begin{tabular}{|c|c|c|c|c|c|c|c|c|}
\hline Config. & $\boldsymbol{V}_{\boldsymbol{I}}$ & $\boldsymbol{V}_{\mathbf{2}}$ & $\boldsymbol{V}_{\boldsymbol{3}}$ & $\boldsymbol{V}_{\boldsymbol{4}}$ & $\boldsymbol{V}_{\boldsymbol{5}}$ & $\boldsymbol{V}_{\boldsymbol{6}}$ & $\boldsymbol{V}_{\boldsymbol{7}}$ & $\boldsymbol{V}_{\boldsymbol{8}}$ \\
\hline $\mathrm{A}$ & $0 \mathrm{~V}$ & $0 \mathrm{~V}$ & $0 \mathrm{~V}$ & $0 \mathrm{~V}$ & $0 \mathrm{~V}$ & $0 \mathrm{~V}$ & $0 \mathrm{~V}$ & $0 \mathrm{~V}$ \\
\hline $\mathrm{B}$ & $30 \mathrm{~V}$ & $-30 \mathrm{~V}$ & $30 \mathrm{~V}$ & $-30 \mathrm{~V}$ & $30 \mathrm{~V}$ & $-30 \mathrm{~V}$ & $30 \mathrm{~V}$ & $-30 \mathrm{~V}$ \\
\hline $\mathrm{C}$ & $50 \mathrm{~V}$ & $-50 \mathrm{~V}$ & $50 \mathrm{~V}$ & $-50 \mathrm{~V}$ & $50 \mathrm{~V}$ & $-50 \mathrm{~V}$ & $50 \mathrm{~V}$ & $-50 \mathrm{~V}$ \\
\hline $\mathrm{D}(15 \mathrm{~mm})$ & $30 \mathrm{~V}$ & $-30 \mathrm{~V}$ & $30 \mathrm{~V}$ & $-30 \mathrm{~V}$ & $30 \mathrm{~V}$ & $-30 \mathrm{~V}$ & $30 \mathrm{~V}$ & $-30 \mathrm{~V}$ \\
\hline $\mathrm{E}(15 \mathrm{~mm})$ & $13 \mathrm{~V}$ & $-17 \mathrm{~V}$ & $17 \mathrm{~V}$ & $-17 \mathrm{~V}$ & $17 \mathrm{~V}$ & -17 & $17 \mathrm{~V}$ & $-13 \mathrm{~V}$ \\
\hline $\mathrm{F}(15 \mathrm{~mm})$ & $0 \mathrm{~V}$ & $0 \mathrm{~V}$ & $0 \mathrm{~V}$ & $0 \mathrm{~V}$ & $0 \mathrm{~V}$ & $0 \mathrm{~V}$ & $0 \mathrm{~V}$ & $0 \mathrm{~V}$ \\
\hline $\mathrm{G}(15 \mathrm{~mm})$ & $40 \mathrm{~V}$ & $0 \mathrm{~V}$ & $40 \mathrm{~V}$ & $0 \mathrm{~V}$ & $40 \mathrm{~V}$ & $0 \mathrm{~V}$ & $40 \mathrm{~V}$ & $0 \mathrm{~V}$ \\
\hline $\mathrm{H}(0 \mathrm{~mm})$ & $15 \mathrm{~V}$ & $-15 \mathrm{~V}$ & $15 \mathrm{~V}$ & $-15 \mathrm{~V}$ & $15 \mathrm{~V}$ & $-15 \mathrm{~V}$ & $15 \mathrm{~V}$ & $-10 \mathrm{~V}$ \\
\hline $\mathrm{I}(0 \mathrm{~mm})$ & $10 \mathrm{~V}$ & $-10 \mathrm{~V}$ & $10 \mathrm{~V}$ & $-10 \mathrm{~V}$ & $10 \mathrm{~V}$ & $-10 \mathrm{~V}$ & $10 \mathrm{~V}$ & $-10 \mathrm{~V}$ \\
\hline
\end{tabular}

\section{OPERATION IN PRESENCE OF THE HCM}

In this section the antenna performance is characterized in the presence of the human core model (HCM) phantom, which mimics a conical volume of the human stomach as explained in [2] (Fig.4). This characterization is important given that the relative permittivity for

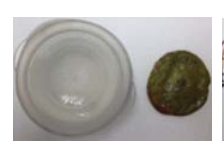

a) b)

c)

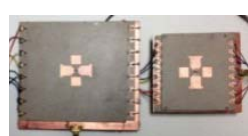

Figure 4. a) HCM consisting of a solid skin-muscle tissue phantom and liquid blood-fatty tissue phantom. Planar size comparison for b) GaAs based tunable antenna and c) BST based tunable antenna. different types of body tissue varies, as well as the separation distance between the sensor antenna and the tissue. Thus, the HCM was placed in contact and at distances up to $15 \mathrm{~mm}$ from the antenna, because experiments performed at USF using a 1.4 $\mathrm{GHz}$ planar antenna showed that the impedance measured at the antenna input varied as $\mathrm{Z}=(60 \pm 30)+\mathrm{j}(-70 \pm 70) \Omega$ over a distance of 0 to $15 \mathrm{~mm}$ from a human hand [2].

In [1] it was demonstrated that the tunability of the GaAs-based antenna successfully corrected for impedance mismatch introduced by the HCM at varying offsets, from 2.2 to $2.8 \mathrm{GHz}$. In The BST-based antenna was subjected to the same test and similar performance was achieved. Figure 5 shows that with a uniform voltage of $30 \mathrm{~V}$ on all rows of the FSS and in free space (Configuration B in Table I), the antenna has a good impedance match from $2.26 \mathrm{GHz}$ to $2.52 \mathrm{GHz}$. When the HCM is placed at a $10 \mathrm{~mm}$ offset from the face of the antenna (Configuration D), the $\mathrm{S}_{11}$ response is changed as depicted in Fig. 5. However, by adjusting the bias voltage at the input lines (Configuration E), the impedance match can be improved. This antenna also demonstrates that when HCM is in contact with the antenna, the impedance matching can be also improved ( $\mathrm{H}$ and $\mathrm{I}$ ). The characteristics of the two antennas are summarized in Table II.

\section{CONCLUSIONS}

A low profile tunable antenna using BST varactors has been demonstrated and compared with a counterpart based on GaAs varactor diodes. The main advantages of the BST antenna are the planar size and mass reduction which are desirable features for portable applications. The BST antenna has lower radiation efficiency than the GaAs based design, due primarily to the lower Q factor of the BST varactors ( $\sim 11$ at $2.4 \mathrm{GHz}$ compared to $\sim 200$ for GaAs). Although the lower efficiency could compromise the noise figure of the radiometer and reduce its sensitivity, the design is highly cost effective, compact, robust, easily tunable and low profile. To improve these results on the next generation antenna, a thicker substrate will be used to increase the magnitude of the FSS reflection coefficient and its efficiency.
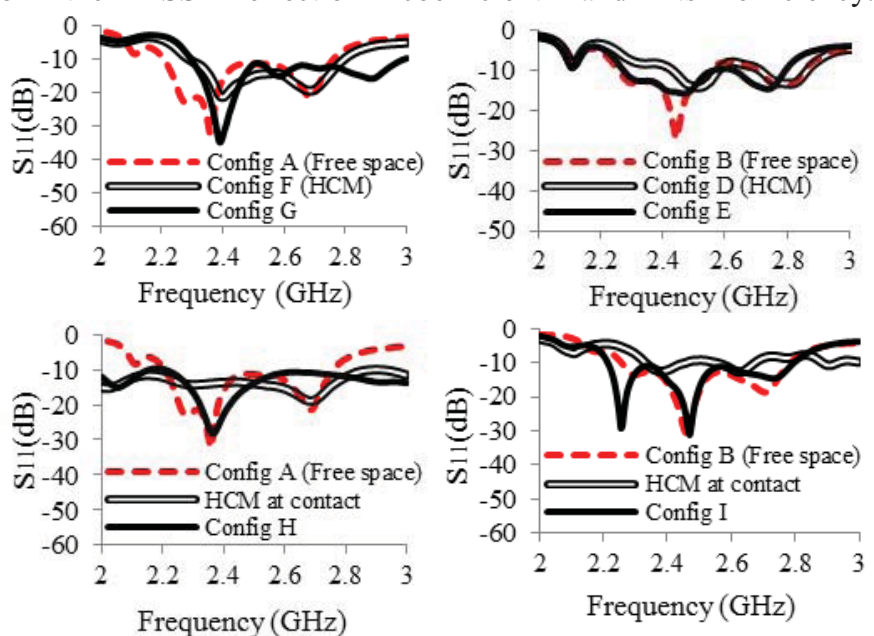

Figure 5. Measured $\mathrm{S}_{11}$ of the antenna in free space, in the presence of the HCM at contact with the antenna (Bottom) and $15 \mathrm{~mm}$ separation (Top) distance when different biases are applied to the diodes.

TABLE II. ANTENNA COMPARISON

\begin{tabular}{|c|c|c|c|c|c|c|c|}
\hline Antenna & $\begin{array}{c}\text { Mass } \\
\text { (gms) }\end{array}$ & $\begin{array}{c}\text { Total } \\
\text { devices }\end{array}$ & $\begin{array}{c}\text { Cost } \\
\text { per } \\
\text { device }\end{array}$ & Cost & $\begin{array}{c}\text { Area } \\
\left.\text { (mm }^{2}\right)\end{array}$ & $\begin{array}{c}\text { Eff. } \\
(\%)\end{array}$ & $\begin{array}{c}\text { Tunable } \\
\text { BW } \\
\left(\mathbf{M H z}^{\prime}\right)\end{array}$ \\
\hline GaAs & 188 & 56 & 50 US\$ & High & 15600 & $50-80$ & 520 \\
\hline BST & 87 & 56 & 0.1 US\$ & Low & 7900 & $30-60$ & 425 \\
\hline
\end{tabular}

\section{REFERENCES}

[1] D. Cure, T. Weller and F.A. Miranda "Study on a Low Profile $2.4 \mathrm{GHz}$ Planar Dipole Antenna Using a 1-D Varactor-Tuned High Impedance Surface," Antennas and Propagation, IEEE Transactions on, vol.61, no.2, pp.1, February 2013

[2] Q. Bonds, J. Gerig, T. Weller, and B. Roeder, "Towards Core Body Temperature Measurement via Close Proximity Radiometric Sensing," IEEE Sensors Journal, Special Issue on Non-Invasive Physiological Monitoring, vol. 12, no. 3, pp. 519-526, March 12. 2012.

[3] K.D. Stephan, and J.A. Pearce, "Antennas and reflectors for near-field radiometric remote sensing of temperature in industrial applications," IEEE Antennas and Propagation Society International Symposium, vol. 4, pp. $302-305$, August 2002.

[4] S. Jacobsen, and P. Stauffer, "Performance Evaluation of Various Antenna Configurations for Microwave Thermography During Superficial Hyperthermia," Journal of Electromagnetism Waves and Applications, vol. 15, no. 1, pp. 111-134, 2001 